If a paper comes within the province of a journal and seems to be scientifically acceptable, an editor's job is the elimination of ambiguity and prolixity. These are matters of fact. An editor can say: "This phrase could mean A or B. Which do you mean?" or "This amounts to so-and-so, which is only half as long as the original." It is no part of an editor's job to insert misconceptions about the English language, however sincerely felt, into someone else's paper.

Yours faithfully, N. W. Pirie

Harpenden, Herts,

\section{Fostering spin-off}

SIR,-It was with much interest that I read the recent paper by Isaacs et al. (January 24) on cyclogenesis by motor vehicle movements. I wonder how many people outside Australia are aware that the Aborigines have been making use of this principle for centuries. Why else would their rain making dances consist of a steady clockwise progression?

Related to this, I am at present working on a theory that the drying up of central Australia followed the invention of the boomerang, whose anticlockwise rotation would inhibit cyclonic activity. As happens with most revolutionary ideas, however, I have been having trouble funding this programme. Yours faithfully,

K. H. Lloyd Salisbury Heights, South Australia.

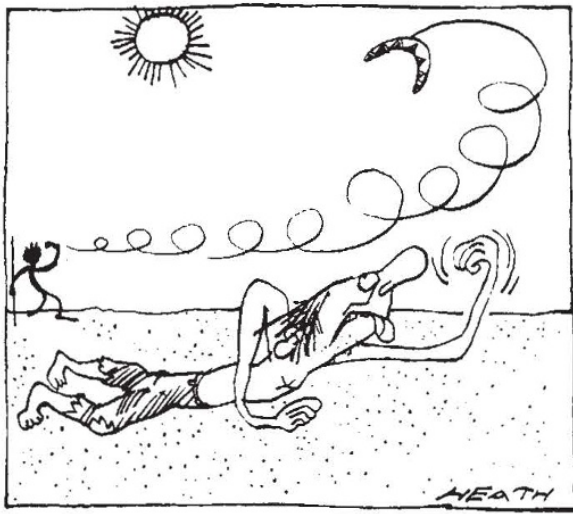

\section{Darwin's cancer research}

SiR,--In considering the scope of subject matter relevant to the study of cancer, Stoker (April 17) suggests that much of cell-oriented biology may have such implications. It may, but it would be shortsighted to stop there. Natural selection has obvious relevance, at least obvious to an evolutionary biologist, and Cairns (May 15) has discussed this explicitly. It has also become central to immunology. My only contribution to oncology came as a direct result of work in palaeoecology. Theoretical frameworks that develop in one subject often have application elsewhere, and this really cannot be foreseen. Would the Imperial Cancer Research Fund have supported Darwin?

Yours faithfully, Leigh Van Valen

University of Chicago,

Chicago, Ill. 60637

\section{Integrity in science}

SIR,-I am sorry that the only comment accompanying my letter (June 12) mainly concerns its occasion and not its essence. I would gladly ignore it, but the claims of truth preclude that luxury.

Mr. Maddox's suggestion that the non-appearance of his leader resulted from the "offensiveness and repugnancy" of the correspondence is false. The article was promised, "before the end of the year", on November 24, 1969. Successive (polite) enquiries from Lord Soper and me brought such replies as "the article is now almost ready" (January 21, 1970); it would be delayed "a week or two" (end of March 1970); until Lord Soper's final inquiry (July 6, 1970) brought no reply-or the article. It had been promised in place of my reply to Professor Synge who had written (Nature, 219, 790; 1968) that "as the result of a lengthy correspondence with Professor Dingle" he and I had agreed that either "the concepts used in the special theory of relativity as ordinarily understood" or "the concept of clocks that run regularly, as understood by Professor Dingle" must be abandoned. Since my concept of such clocks has never been represented as other than an instrument so recognised by a standard observatory, the only relevant property I required being an inability of one to run concurrently both faster and slower than another, it was now clearly mate in one move. Maddox made that move impossible by steadfastly suppressing my rejoinder; it has never appeared. (Incidentally, his statement now that I have "shifted my ground" since 1968 is here seen clearly to be false: Synge's diagnosis is identical with my position as stated in my recent letter).

Maddox should have quoted more of my letter of April 6, 1971; it ran: "In view of the failure of all other means of getting a straightforward answer to my criticism of special relativity ... I have been, with great reluctance, forced to the extreme measure of writing a book describing the course of the whole series of evasions ... I write this final letter, which will be included in the book if necessary, to invite you to give your own explanation of your attitude, which I promise to include verbatim. I repeat what I have said before-that my sole object is to get this matter settled, first of all with absolute openness and avoidance of all further evasion and quibbling, and secondly, provided that that is done, with the minimum of sensation and unpleasantness. Action on your part, even now, would make a full exposure of the ethical aspect of the matter unnecessary". Your readers can judge whether the "offensiveness and repugnancy" of this letter adequately excuse the succession of broken promises a year earlier.

There was a sequel to "the recent incident" as related by Mr. Maddox. The author of the article mentioned subsequently asked for his side of the story (although, since it had already appeared in the Editorial, this might well seem redundant) and was given a vague statement that implied, if anything, that the "promises" ascribed to me had another source than that which he now owns, which was "even more full of somewhat unrealistic threats". I know of no letter which can be so interpreted. It was to prevent a recurrance of such misrepresentation and for that reason alone that $I$ felt it necessary to record the actual facts.

I suppose I must reply once more to the charge that "Dingle's confusion stems from his assertion that special relativity requires that the differences of rate should 'actually and not merely apparently' occur. The truth, of course, is quite the opposite." Whenever the special relativity effects of motion are invoked to predict or explain something observable (for example, asymmetrical ageing, cosmic-ray behaviour . . . ) they are held to be "actual", whenever this leads to a contradiction they become only "apparent"; and anyone to whom this is unacceptable is deceived by "commonsense". The letter I have called "L" completely refutes Maddox's statement. His technical example involving "lasers" and "algorithms" refers to a completely different phenomenon which has nothing at all to do with the matter.

I withhold comment on the rest of Maddox's letter, remembering what Shakespeare said about painting the lily, and leave your readers to judge whether Maddox is right in denying that there is "an ethical issue" here. I am sure, however, that the many who agree with me that there is, will require a plain, direct answer to my question if they are to retain their trust in the integrity for which the scientific world has in the past been justly noted. I most earnestly hope that among those with authority and responsibility in this matter, there will not be wanting someone ready to have done with "doublethinking", to clear his mind and words of cant, and to exhibit the candour and courage needed to provide such an answer.

\section{Yours faithfully,} Herbert Dingle

Purley, Surrey 